Guilherme Lages SAVASSI-

$\mathrm{ROCHA}^{1}$

Ney Luis PIPPI ${ }^{1}$

Rosana Keller RICHTER ${ }^{1}$

Carmen Lice Buchmann

GODOY ${ }^{1}$

Ângela Patricia Medeiros

VEIGA ${ }^{1}$

Ana Neri Christo de

OLIVEIRA ${ }^{1}$

Sheila Francheska da Silva

CAMARGO ${ }^{1}$

Charles PELIZZARI ${ }^{1}$

André Luis Lima de

OLIVEIRA ${ }^{1}$

Ademar Luis DALLABRIDA ${ }^{1}$

Eduardo Santiago Ventura

de AGUIAR ${ }^{1}$

Simone BOPP 1

\section{Correspondência para:}

Guilherme Lages Savassi Rocha

Rua São João Evangelista, n 233, ap. 301 ,

Bairro São Pedro Belo Horizonte - MG

30330140 - Tel.: 031875907 40,

e-mail: guilhermesavassi@hotmail.com

Recebido para publicação: 06/11/2003 Aprovado para publicação: 23/08/2007

\title{
Ureteroneocistostomia extravesical modificada pela sondagem ureterovesical peroperatória no autotransplante renal em cães
}

\author{
1 - Curso de Medicina Veterinária da Universidade Federal de Santa Maria, \\ Santa Maria-RS
}

\section{Resumo}

Realizou-se, em sete cães adultos, o autotransplante renal esquerdo associado à nefrectomia contralateral para avaliação da técnica de ureteroneocistostomia extravesical modificada pela sondagem ureterovesical peroperatória. Durante a sutura do ureter na bexiga, foi mantida uma sonda uretral na região da anastomose ureterovesical, o que facilitou a realização da técnica cirúrgica e permitiu a confecção de anastomose de diâmetro adequado. A avaliação do rim transplantado e do ureter correspondente foi feita mediante ultra-sonografia a cada sete dias durante as seis primeiras semanas de pós-operatório, período em que também se fez o exame clínico diário de todos os animais. No último dia $\left(42^{\circ}\right)$ da avaliação a curto prazo, realizou-se a urografia excretora. Em seguida, manteve-se acompanhamento clínico periódico dos sete cães por um período mínimo de quatro meses, sem que fosse detectada qualquer alteração digna de nota. A técnica de reconstrução do trato urinário utilizada mostrou-se eficiente, não se observando nenhuma complicação urológica no pós-operatório de todos os animais.

\section{Introdução}

O transplante renal bem-sucedido é o tratamento mais adequado para a insuficiência renal crônica. ${ }^{1,2} \mathrm{O}$ sucesso do procedimento na espécie humana tem estimulado proprietários de cães e gatos a considerarem essa opção no tratamento de seus animais. ${ }^{3}$

A técnica cirúrgica adotada com maior freqüência consiste no implante do rim esquerdo na fossa ilíaca direita do indivíduo receptor. O primeiro tempo cirúrgico praticado é a anastomose da veia renal com a veia ilíaca externa, realizada no padrão término-lateral. ${ }^{4,5,6} \mathrm{Em}$ seguida, a artéria renal é suturada à artéria ilíaca externa, no padrão término-terminal, utilizando fio de polipropileno 7-0. Inicialmente, colocamse dois pontos isolados simples em $180^{\circ} \mathrm{e}$, em seguida, realiza-se uma sutura contínua entre eles. ${ }^{4,7}$

Após a síntese vascular, a continuidade do trato urinário deve ser restaurada. Para isso são utilizadas, de acordo com Knechtle ${ }^{8}$, duas técnicas cirúrgicas: a de PolitanoLeadbetter (ureteroneocistostomia intravesical) e a de Lich-Gregoir (ureteroneocistostomia extravesical). Cada uma dessas técnicas se associa às complicações pós-operatórias até certo ponto específicas. A ureteroneocistostomia deLich-Gregoir relaciona-se a um maior índice de fístula e refluxo urinário, ao passo que a de Politano-Leadbetter implica maior risco de obstrução ureterovesical. ${ }^{9}$

De acordo com a técnica de ureteroneocistostomia intravesical (PolitanoLeadbetter), após a cistotomia, o ureter, introduzido na bexiga por um túnel na submucosa, é fixado na camada mucosa. No caso da técnica extravesical (LichGregoir), sutura-se o ureter diretamente na mucosa com fio absorvível 5-0, após incisão vesical seromuscular. Ou seja, cria-se um "defeito" na mucosa, onde o ureter é suturado. Posteriormente, realiza-se uma 
sutura seromuscular, vedando a anastomose ureterovesical. 9,10,11

Atualmente, dá-se preferência à técnica extravesical (Lich-Gregoir) em função da maior incidência e gravidade das complicações urológicas relacionadas à de Politano-Leadbetter. ${ }^{12} \mathrm{~A}$ técnica extravesical é de confecção mais fácil, é minimamente invasiva, exige menor dissecação tecidual, implica menor manipulação e diminui o risco de trauma do ureter distal, além de necessitar de um segmento ureteral menor para o reimplante. ${ }^{13}$

Tendo em vista que as complicações urológicas mais comuns após o transplante renal - fístula, estenose e refluxo - relacionamse com a anastomose ureterovesical, outras técnicas cirúrgicas vêm sendo pesquisadas. A pieloureterostomia foi realizada por Salomon et al. ${ }^{14}$ para a correção de complicações pós-operatórias de anastomoses ureterovesicais. Esse procedimento consiste na utilização do ureter do indivíduo receptor para anastomose na pelve do rim transplantado. De acordo com os autores, a pieloureterostomia é um tratamento seguro para as complicações pós-operatórias citadas.

A anastomose uretero-ureteral término-terminal foi citada por Faenza et al. ${ }^{15}$ como outra solução para tratar ou evitar a estenose do ureter. Nessa técnica, utiliza-se uma porção do ureter do doador e outra do receptor.

As complicações cirúrgicas representam grande parcela dos problemas encontrados no transplante renal em cães, sendo as mais comuns: falha renal por isquemia prolongada, complicações vasculares, refluxo urinário, complicações referentes ao implante do ureter na bexiga e infecção. ${ }^{16}$

As complicações urológicas após um transplante renal ocorrem em cerca de 2,5 a $14,7 \%$ dos casos, podendo este índice chegar a 30\%. Fístula e obstrução urinárias são os problemas mais comuns no pós-operatório, predispondo à infecção, rejeição aguda do órgão e ruptura do parênquima. A estase urinária propicia a formação de hidroureter e, posteriormente, hidronefrose, com aumento na concentração sérica da creatinina. $17,18,19$

O refluxo urinário é uma das complicações mais freqüentes após a ureteroneocistostomia. ${ }^{14}$ Os pacientes que já apresentavam refluxo vesicoureteral ou que o desenvolveram após o transplante, correm maior risco de infecção ascendente do trato urinário, podendo haver perda da função do órgão. ${ }^{20,21}$

Dentre os exames utilizados para avaliação do fluxo urinário, destacam-se a ultra-sonografia e a urografia excretora. ${ }^{22}$

As complicações urológicas freqüentemente diagnosticadas pela ultrasonografia são obstrução ureteral, infecções, refluxo e fístulas urinárias. ${ }^{23}$ Para monitoração dessas possíveis alterações, deve-se realizar o referido exame até a sexta semana após o transplante. ${ }^{24,25}$

Levando-se em consideração que a maioria das complicações urológicas do transplante renal devem-se a falhas na anastomose ureterovesical, faz-se necessário o estudo de novas técnicas cirúrgicas capazes de minimizá-las.

Desta forma, realizou-se modificação na técnica de ureteroneocistostomia extravesical com o objetivo de diminuir a ocorrência das complicações urológicas não raro observadas no pós-operatório do transplante renal, evitando a formação de fístula na junção vesicoureteral, impedindo o desenvolvimento de refluxo e a ocorrência de obstrução do fluxo urinário.

\section{Material e Método}

Foram utilizados sete cães machos, adultos, sem raça definida, clinicamente saudáveis, com peso variando entre 15 e 25 kg. O manejo dos animais foi realizado segundo orientações do Comitê de Ética em Pesquisa (CEP / UFSM). O processo de seleção dos animais fundamentou-se no exame clínico, na urinálise, em dosagens séricas de uréia e creatinina, no hemograma, na contagem de plaquetas e na ultrasonografia. O pré-operatório consistiu em banho, tricotomia e fluidoterapia com 
Ringer-lactato $(60 \mathrm{ml} / \mathrm{kg} / \mathrm{dia})$ no dia anterior à operação.

Como medicação pré-anestésica utilizou-se a acepromazina (Acepran ${ }^{\circledR}$, Univet, São Paulo-SP) $(0,05 \mathrm{mg} / \mathrm{kg})$ e o citrato de fentanila (Fentanest ${ }^{\circledR}$, Cristália, Itapira-SP) $(0,003 \mathrm{mg} / \mathrm{kg})$. A indução foi feita com tiopental sódico (Thiopentax ${ }^{\circledR}$, Cristália, Itapira-SP) $(12,5 \mathrm{mg} / \mathrm{kg})$, pela via intravenosa. Após a intubação orotraqueal, aplicou-se sulfato de morfina (Dimorf ${ }$, Cristália, Itapira-SP) $(0,1 \mathrm{mg} / \mathrm{kg})$ pela via epidural, com o intuito de proporcionar analgesia no pós-operatório imediato. A manutenção anestésica foi feita por via inalatória com halotano (Halothano ${ }^{\circledR}$, Cristália, Itapira-SP) em oxigênio a 100\%. Quando necessário, administrou-se citrato de fentanila $(0,002 \mathrm{mg} / \mathrm{kg}$, IV) para melhorar ainda mais a qualidade da analgesia. A fluidoterapia com Ringer-lactato $(20 \mathrm{ml} / \mathrm{kg} / \mathrm{h})$ foi mantida durante todo o procedimento.

O primeiro tempo cirúrgico consistiu na dissecação da artéria e da veia ilíaca externa, com remoção da camada adventícia vascular nos segmentos onde seriam feitas as anastomoses. Em seguida, o ureter esquerdo foi isolado do peritônio por dissecação romba e o rim correspondente removido mediante ligadura distal da artéria e veia renais.

Logo após a nefrectomia esquerda iniciou-se, por meio de um cateter periférico $\mathrm{n}^{\circ} 22$ ( BD Angiocath, Juiz de Fora-MG) inserido na artéria renal, a infusão da solução de conservação Euro-Collins (Euro Collins (B) Fresenius Kabi, São Paulo-SP) resfriada a $4^{\circ} \mathrm{C}$, dando início ao período de isquemia fria. Foi criado um "defeito" na veia ilíaca externa direita, realizando-se a anastomose com a veia renal no padrão término-lateral, com fio de polipropileno 6-0 (Propilene ${ }^{\circledR}$ Toppoint ,Cirumédica, Cotia-SP). Em seguida, realizou-se a anastomose términoterminal entre a artéria renal e o coto proximal da artéria ilíaca externa, também com fio de polipropileno 6-0.

A reconstrução do trato urinário foi realizada em seguida, utilizando-se a técnica de ureteroneocistostomia extravesical acrescida de uma modificação. Uma sonda uretral (Embramed ${ }^{\circledR}$, São Paulo-SP) no 4 foi seccionada transversalmente em sua extremidade distal, introduzida no ureter e impulsionada em direção à pelve renal. A outra extremidade da sonda foi apreendida com uma pinça hemostática de Halstead e introduzida por um defeito criado na mucosa vesical onde o ureter foi suturado posteriormente. A sonda percorreu o interior da bexiga e saiu por uma pequena incisão vesical contralateral, funcionando como um "stent" temporário, ou seja, permaneceu dentro da região da sutura como um suporte para a anastomose (Figura 1).

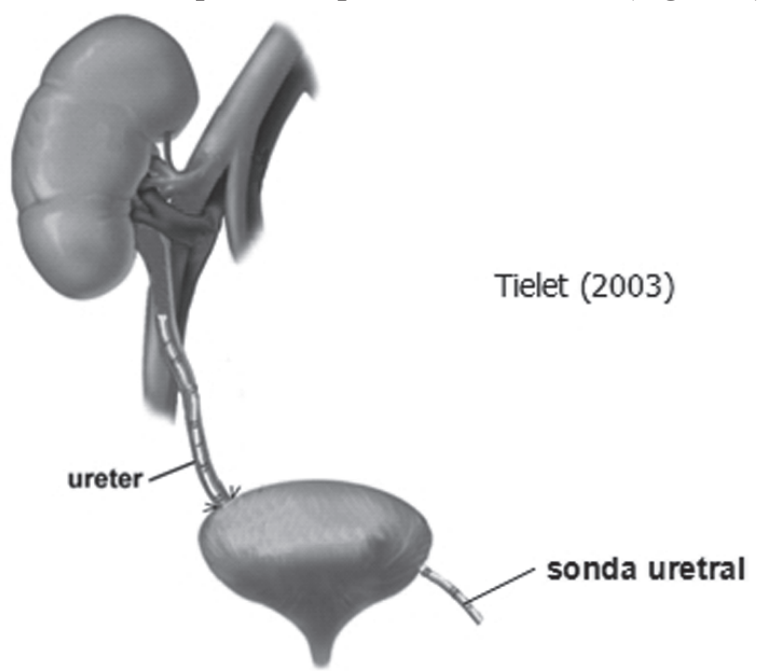

Figura 1 - Ureteroneocistostomia extravesical modificada com sondagem ureterovesical durante a anastomose 
A presença da sonda dentro do ureter permitiu também a drenagem de urina que já estava sendo produzida pelo rim transplantado (Figura 2), cerca de 10 minutos após o restabelecimento do fluxo sangüíneo

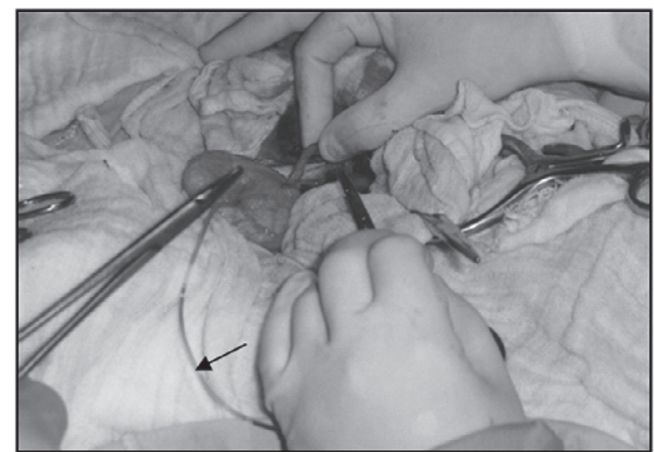

Figura 2 - Drenagem de urina do rim transplantado pela sonda uretral (seta), inserida no ureter

renal. Para o implante do ureter na bexiga foram utilizados dois reparos em $180^{\circ} \mathrm{e}$ sutura contínua, com fio de poligliconato 6 0 (Ethicon ${ }^{\circledR}$, Johnson \& Johnson, São José dos Campos-SP) (Figura 3).

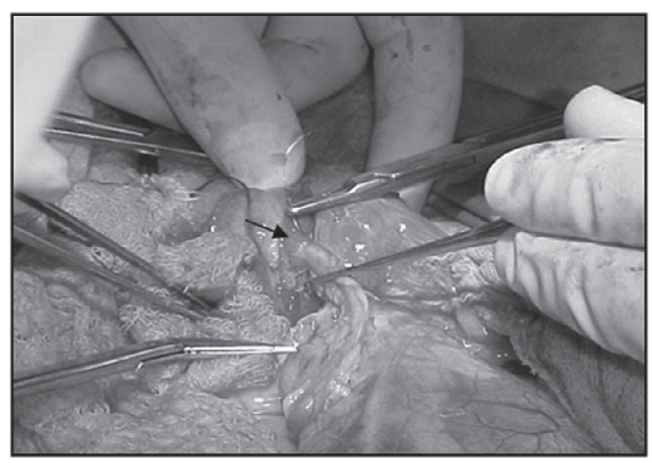

Figura 3 - Anastomose ureterovesical (seta)

Ao final da anastomose ureterovesical, realizou-se um plano de sutura das camadas serosa e muscular de forma a criar um túnel anti-refluxo, com pontos simples separados e fio de poliglactina $910 n^{\circ}$ 3-0 (Ethicon ${ }^{\circledR}$, Johnson \& Johnson, São José dos Campos$\mathrm{SP})$. A sonda foi então removida pela incisão contralateral.

Em seguida, foi realizada nefropexia ao peritônio utilizando-se pontos simples separados, com fio de poliglactina $910 \mathrm{n}^{\circ}$ 3-0, e o rim direito foi removido. A nefrectomia total direita foi feita para que toda a produção urinária do animal fosse proveniente do rim transplantado, facilitando assim a avaliação da função desse órgão. A laparorrafia foi feita no padrão simples separado com fio de poliglactina $910 \mathrm{n}^{\circ} 2-0$.

A ultra-sonografia foi realizada a cada sete dias durante as seis primeiras semanas de pós-operatório, com o objetivo de avaliar a morfologia do órgão transplantado e a produção urinária. Durante esse período, os animais foram submetidos a exame clínico diário. No último dia da avaliação a curto prazo ( $42^{\circ}$ dia pós-operatório), realizou-se a urografia excretora. Com o intuito de facilitar a visibilização da junção ureterovesical, foi associada a técnica de pneumocistografia, com ar ambiente, no volume de $6 \mathrm{ml} / \mathrm{kg}$.

Terminada a sexta semana de pósoperatório, todos os animais foram doados e, a partir de então, manteve-se monitoração clínica periódica, para avaliação dos resultados do transplante a médio prazo. $\mathrm{O}$ tempo de observação dos animais variou entre quatro e nove meses, de acordo com a data da operação de cada um deles.

\section{Resultados e Discussão}

Nenhuma complicação urológica foi diagnosticada pelo exame ultra-sonográfico durante as seis semanas de avaliação de todos os cães. Embora tenha ocorrido aumento volumétrico do órgão, não foi observada qualquer dilatação da pelve renal, o que configuraria quadro de hidronefrose, que também se acompanha de aumento do volume do rim. ${ }^{23}$

De acordo com a urografia excretora, também não se verificou nenhuma complicação urológica ou alteração funcional do órgão no pós-operatório dos sete animais. Houve boa opacificação do parênquima renal, com a visibilização das regiões cortical e medular bem como do ureter até a sua inserção na bexiga, o que indica perfusão satisfatória do órgão. ${ }^{26}$

A urografia excretora permitiu adequada avaliação do tamanho, da superfície e do contorno do rim e do ureter (Figura 04). Nenhuma alteração clínica foi 


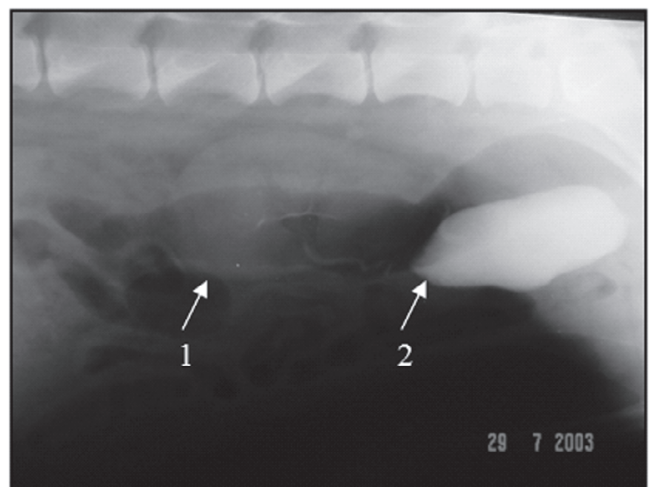

Figura 4 - Urografia excretora no $42^{\circ}$ dia pós-operatório ( 1 - rim transplantado ; 2 - contraste na bexiga)

evidenciada a curto ou a médio prazo após a intervenção cirúrgica.

As dosagens séricas de uréia e creatinina, obtidas até o $42^{\circ}$ dia pósoperatório, não apresentaram diferença estatística significativa, indicando função renal adequada (Figuras 5 e 6 ).

A técnica de implante do ureter com a sondagem ureterovesical mostrou ser procedimento de fácil execução, possibilitou a confecção da anastomose ureterovesical de diâmetro adequado e evitou a drenagem de urina para a cavidade abdominal durante a sutura do ureter.

Não foi diagnosticada nenhuma complicação urológica no pós-operatório de todos os animais. A ureteroneocistostomia extravesical convencional, por sua vez, relaciona-se à ocorrência de fístula e refluxo urinário em cerca de 2,5 a 14,7\% dos casos, podendo este índice chegar a 30\%. ${ }^{9,17}$

A sonda uretral, mantida na região da anastomose ureterovesical no peroperatório, funcionou como um molde para a sutura do ureter na bexiga, facilitando a execução da técnica cirúrgica e servindo como um "stent" temporário. A utilização de "stents" ou próteses tubulares na junção ureterovesical tem sido recomendada para

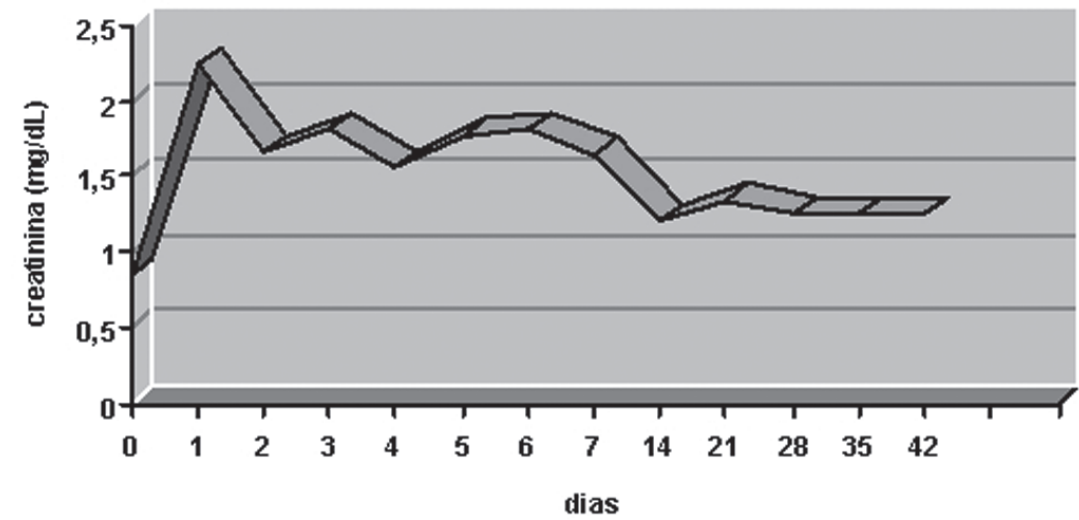

Figura 5 - Dosagem sérica de creatinina $(\mathrm{mg} / \mathrm{dl})$ até o $42^{\circ}$ dia pós-operatório

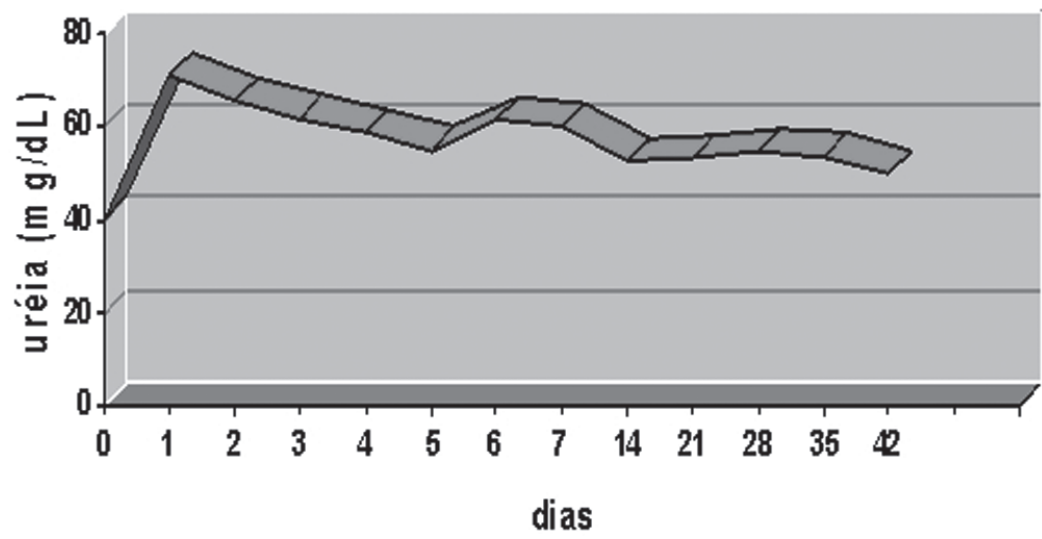

Figura 6 - Dosagem sérica de uréia $(\mathrm{mg} / \mathrm{dl})$ até o $42^{\circ}$ dia pós-operatório 
tratar ou prevenir as complicações urológicas do transplante renal. 27,28 Porém, a permanência dessas próteses durante os primeiros dias de pós-operatório pode predispor à obstrução ureteral pela deposição de coágulos ou cristais em seu interior, impondo-se sua remoção imediata, para prevenir graves conseqüências à função do enxerto. ${ }^{29} \mathrm{~A}$ utilização da sonda como um "stent" temporário, ou seja, sua remoção ao término da anastomos e ureterovesical, evitou semelhante complicação. Além disso, a presença da sonda dentro do ureter no peroperatório permitiu a drenagem da urina produzida pelo rim transplantado, possibilitando a monitoração precoce da função do enxerto e impedindo o escoamento da urina para a cavidade abdominal.

\section{Conclusão}

A ureteroneocistostomia extravesical com sondagem ureterovesical peroperatória é técnica adequada para a reconstrução do trato urinário no transplante renal em cães, não se acompanhando de complicações urológicas no pós-operatório e permitindo a monitoração precoce da função do enxerto.

Agradecimentos ao meu orientador Prof Ney Luis Pippi, à equipe do Laboratório de Cirurgia Experimental da UFSM (Lace) e ao Programa de Pós-Graduação em Medicina Veterinária da UFSM pelo apoio e incentivo na realização deste trabalho.

\title{
Ureteroneocistostomia extravesical modificada pela sondagem ureterovesical peroperatória no autotransplante renal em cães
}

\begin{abstract}
To test a modified extravesical ureteroneocystostomy using a urethral probe like a stent just on the peroperative time, seven adult mongrel dogs underwent bilateral nephrectomy followed by unilateral autotransplantation. The other kidney was discarded. The evaluation of the animals was made by ultrasonography and clinical exams for the first six weeks after the surgery. The excretory urography was made on the end of this period. Then, the clinical exams were done by at least four months in each dog, without any complication. The technique of urinary tract reconstruction was considered efficient, without urological complications on the postoperative time of all the dogs.
\end{abstract}

Key words: Allograft. Surgery. Technique. Kidney. Ureter.

\section{Referências}

1 SALOMÃO, F. ${ }^{\circ}$ A. et al. Transplante renal In: PEREIRA, W. A. Manual de transplantes de órgãos e tecidos. 2. ed. Rio de Janeiro: Medsi, 2000. cap. 10, p. 177-201.

2 JOHNSTON, T. D. Renal transplantation. Medicine Journal, v.3, n.5, p. 2-11, 2002.

3 MATHEWS, K. A. et al. Kidney transplantation in dogs with naturally occuring end-stage renal disease. Journal of American Animal Hospital Association, n. 36, p. 294-301, 2000.

4 PIPPI, N. L. Contribuição ao estudo da técnica cirúrgica do auto e homotransplante renal heterotópico em cães. 1970. Dissertação (Mestrado em Medicina Veterinária) - Universidade Federal de Minas Gerais, Belo Horizonte, 1970.

5 BECKMAN, N. J. et al. Kidney transplantation: a therapy option. Clinical Issues in Critical-Care Nursing, v. 3, n. 3, p. 570-584, 1992.

6 HUMAR, A. et al. Kidney transplantation: a brief review. Frontiers in Bioscience, n. 2, p. 41-47, 1997.

7 NÉMETH, T. et al. Principles of renal transplantation in the dog: a review. Acta Veterinaria Hungarica, v. 45, n. 2, p. 213-26, 1997.

8 KNECHTLE, S. J. Ureteroneocystostomy for renal transplantation. Journal of American College of Surgeons, v. 188, n. 6, p. 707-709, 1999. 
9 BEYGA, Z. T.; KAHAN, B. D. Surgical complications of kidney transplantation. Journal of Nephrology, v. 11, n. 3, p. 137-145, 1998.

10 LICH, R.; HOWERTON, L. W.; DAVIS, L. A. Recurrent urosepsis in children. Journal of Urology, n.86, p. 554-555, 1961.

11 JUNJIE, M. et al. Urological complications and effects of double-J catheter in ureterovesical anastomosis after cadaveric kidney transplantation. Transplantation Proceedings, n. 30, p. 3013-3014, 1998.

12 PUBILLONES, I. C. et al. Complicaciones urológicas de los transplantes renales: influencia de las técnicas de ureteroneocistostomia y el uso del tutor ureteral. Revista Urología Panamericana, v. 11, n. 3, 1999.

13 BONFIM, A. C. et al. Fístula urinária após transplante renal. Sinopse de Urologia, n. 1, p. 3-8, 2001.

14 SALOMON, L. et al. Results of pyeloureterostomy after ureterovesical anastomosis complications in renal transplantation. Urology, v. 53, n. 5, p. 908-912, 1999.

15 FAENZA, A. et al. Ureteral stenosis after kidney transplantation: intervention radiology or surgery? Transplantation Proceedings, v. 33 , n. $1 / 2$, p. 2045 2046, 2001.

16 BOVEE, K. C. Renal Transplantation. Veterinary Clinics of North America: Small Animal Practice, v. 14, n. 1, p. 133-137, 1984.

17 MÄKISALO, H. et al. Urological complications after 2084 consecutive kidney transplantations. Transplantation Proceedings, n. 29, p. 152-153, 1997.

18 DELIN, G.; BULANG, H. A new surgical technique of vesicoureteric anastomosis in renal transplants (80 reports). Transplantation Proceedings, v. 30, n. 7, p. 3010-3012, 1998.

19 LYEROVÁ, L. et al. The urinary tract in graft recipients and urologic complications after kidney transplantation. Rozhl Chir, v. 80, n. 7, p. 356-360, 2001.
20 BJORLING, D. E.; CHRISTIE, B. A. Ureters. In: SLATTER, D. Textbook of small animal surgery. 2nd. ed. Philadelphia: Saunders, 1993. v. 2, cap. 105, p. 1443-1450.

21 ERTURK, E. et al. Outcome of patients with vesicoureteral reflux after renal transplantation: the effect of pretransplantation surgery on posttransplant urinary tract infections. Urology, v. 51, n. 5, p. 27-30, 1998. Supplement.

22 SHOKEIR, A. A.; EL-HAMMADY, S. A novel technique of ureteroneocystostomy (extravesical seromuscular tunnel): an experimental study in dogs. II Optimization of surgical technique. Urology, v. 48, n. 6, p. 917-922, 1996.

23 BAXTER, G. M. Ultrasound of renal transplantation. Clinical Radiology, n. 56, p. 802-818, 2001.

24 SAGALOWSKY. A. I. et al. Renal transplantation. In: GILLENWATER, J. Y. Adult and pediatric urology. 2nd.ed. St Louis: Mosby, 1991. v. 1, cap. 24, p. 815852.

25 GROSSKI, D. J. et al. Is postoperative cistography necessary after ureteral reimplantation? Urology, v. 58, n. 6, p. 1041-1044, 2001.

26 TRIOLO, A. J.; MILES, K. G. Renal imaging techniques in dogs and cats. Symposium on diagnostic imaging techniques. Veterinary Medicine, v.90, n.10, p. 959-966, 1995.

27 KUMAR, A. et al. Significance of routine JJ stenting in living related renal transplantation: a prospective randomized study. Transplantation Proceedings, $\mathrm{n}$. 30, p. 2995-2997, 1998.

28 SALAHI, H. et al. The efficacy of ureteral stents in prevention of urological complications in renal transplantation. Transplantation Proceedings, n. 33, p. 2668, 2001.

29 KHAULL, R. B.; AYVAZIAN, P. J. Modified extravesical ureteroneocistostomy and routine ureteral stenting in renal transplantation: Experience in 300 consecutive cases. Transplantation Proceedings, v. 33, n. 5, p. 2665-2666, 2001. 